\title{
Mitigation of the alternative energy for the wind farm center considering temperature and wind speed
}

\author{
Rima Septiani Prastika ${ }^{1, *}, A . N$. Afandi ${ }^{2, \mathrm{~b}}$, Dwi Prihanto ${ }^{2, \mathrm{c}}$ \\ ${ }^{1}$ Electrical Engineering Graduate Program, Universitas Negeri Malang, Malang, 65145 Malang, \\ Indonesia \\ ${ }^{2}$ Electrical Engineering Department, Universitas Negeri Malang, Malang, 65145 Malang, Indonesia
}

\begin{abstract}
Recently, electric usages are increasing every year by year in many sectors. In facts, fossil fuels have been fueled to produce electrical energy availability at many power plants which are very limited for the sustainable procurement. Developing and implementing renewable energy sources should be urgently promoted to reduce the dependence on fossil fuels that have been fueled to generate electricity for the long period throughout various power plant combinations. In expectation, the natural source of electrical energy which environmentally friendly and easy to obtain in nature is recommended to explore for the existing energy producers. The natural source of energy can be operated as an alternative power plant to reduce environmental effects and to decrease air contaminants. These works cover those opportunities. In these studies, the method used is a quantitative category with collected primary and secondary data for all evaluations and mitigations. In general, these works are also designed for identifying problems and looking for literature, data collection, processing stage, analysis phase, and final conclusion. The data used is defined in terms of temperature, air pressure, and wind speed. The collected data are supposed to the Purwoharjo City of Banyuwangi Regency, with 10 meters above ground level. Naturally, the wind speed is about $3.5 \mathrm{~m} / \mathrm{s}$ to $4 \mathrm{~m} / \mathrm{s}$ and the average temperature is $300^{\circ}$ Kelvin. The potentially generated wind energy at a single point of coordinates is around $85.17 \mathrm{Wh}$.
\end{abstract}

\section{Introduction}

Based on the electrical energy selling in 2014 amounted to $198,601,78 \mathrm{GWh}$ while in 2015 amounted to 202,845.82 GWh, it is an experience for an increased energy of 4,244.04 GWh. Increasingly the need for electrical energy by the community or consumer electricity requires the emergence of new ideas to generate alternative energy as a replacement source of electricity [1]-[5]. This alternative potential energy source can be explored as a renewable energy source in nature and the amount is unlimited in nature with various mitigated types. In contrast, the fossil fuels have been fueled to produce electricity, where

\footnotetext{
*Corresponding author: rimaseptianiprastika@gmail.com
} 
the amount is limited in nature and belong to non-renewable [6]-[10]. This condition is needed to replace in various usages at power plants. Therefore, the presence of alternative energy is very potential to be an alternative energy solution for electricity generation, especially wind energy [11]-[16]. Naturally, the wind is a moving air and has air pressure affected by the temperature of the air. Wind is a natural resource that can be utilized as an alternative electric energy in the form of wind energy. By considering this alternative energy, natural energy needs for the electricity usages can be lightened bit by bit considering natural potential sources. In particular, it is also necessary to understand the influence of temperature and wind speed on the potential of wind energy [17]-[20].

Basically, Temperature is one of the quantities used to express the heat or cold of a substance. The temperature at which all systems in a thermally balanced state can be expressed in a number of thermal potential energy source [17], [21], [22] Moreover, the thermal potential source will affect the wind energy generated by the wind speed in the conditioned environment [21], [23]-[26]. In particular, a wind speed is a quantity to express the value of the moving air movement. Technically, the wind speed is the distance of air movement per unit of time and it is expressed in meters per second $(\mathrm{m} / \mathrm{s})$, kilometers per hour $(\mathrm{km} / \mathrm{h})$, and miles per hour $(\mathrm{mi} / \mathrm{h})$ equals $\mathrm{knot}(\mathrm{kt})$ which is defined $1 \mathrm{kt}$ equal to 1.85 $\mathrm{km} / \mathrm{h}$ [3]. Moreover, wind speed is measured for the wind in the environment with the unit $\mathrm{m} / \mathrm{s}$. This potential source is used to facilitate the process of calculation and analysis. Wind speed determines the size of the wind force. The faster wind blows to lead to the greater power measured using an anemometer.

By concerning the potential wind speed, one of the potential districts is Banyuwangi Regency where this city has a potential area for wind energy. Geographically, this region is located at the eastern tip of Java Island with the astronomical location between $7^{\circ} 43^{\prime}-8^{\circ} 46^{\prime}$ North Latitude and $113^{\circ} 53^{\prime}-114^{\circ} 38^{\prime}$ Longitude East [4]. The wind potential sources cover an average wind speed by 2.4 knots equivalent to $1.2 \mathrm{~m} / \mathrm{s}$, and an average air pressure of 0.9 atm. In particular, the average air temperature is presented in $28.3^{\circ} \mathrm{C}$ or $301.3^{\circ} \mathrm{K}$. Technically, the potential sources at 10 meter of the wind speed above ground can be utilized to produce electricity at least $1.6-3.3 \mathrm{~m} / \mathrm{s}$ and a maximum speed of $13.9-17.1 \mathrm{~m} / \mathrm{s}$ [2], [25], [27]-[29]. From this condition, the average wind speed in Banyuwangi Regency can potentially be utilized as an environmentally friendly alternative energy that can generate electricity. Furthermore, the process of converting wind energy into electrical energy is called in the wind energy conversion. Conversion of wind energy into electrical energy is worked by utilizing wind energy to rotate the rotor on wind turbines, then wind turbines drive generators that will generate electrical energy [14], [30]-[32]. These works are addressed to an analysis of the influence of temperature and wind speed to wind energy potential sources as alternative wind power plants.

\section{Thermal and Wind Potentials}

As mentioned before that wind is a moving air naturally and it has air pressure which is affected by the temperature of the air. Furthermore, the wind is a natural resource that can be utilized as an alternative electric energy in the form of wind energy [28], [30], [31]. The processed procedures for converting potential energy may be detailed in a windmill conversion using Equation 1.

$\mathrm{E}_{\mathrm{a}}=1 / 2 \cdot \mathrm{C}_{\mathrm{p}} \cdot \rho \cdot \mathrm{D}^{2} \cdot \mathrm{v}^{3} \cdot \mathrm{t}(\mathrm{Wh})$

where $E_{a}$ is wind energy generated by windmill (Wh), $C_{p}$ is a power coefficient $(0.593), \rho$ is the density of air $\left(\mathrm{kg} / \mathrm{m}^{3}\right), \mathrm{D}$ is a diameter of windmill $(\mathrm{m}), \mathrm{v}$ is a wind speed $(\mathrm{m} / \mathrm{s})$, and $\mathrm{t}$ is the time (hour). 
Technically, wind speeds can be used to mitigate the potential sources around 10 meters above ground level which produce in $1.6-17.1 \mathrm{~m} / \mathrm{s}$ [24], [32]-[35]. This speed is covered within the minimum grade 3 and maximum 8 . In addition, the same classification can be seen in Table 1. Since the arm length affects greatly to turbine performances, the shorter arm increases the turbine speed. One of the types is approached using a diameter of 2 meters of the windmill as provided in a wind turbine [36]-[39]. This type allows the maximum permissible blade in 3 meters for the diameter. The type of the wind turbine is assumed to be a horizontal-type where horizontal vane axle wind turbine is the most common wind turbine use that can be applied for the wide rate of speed. Moreover, the enabling high-speed energy, as usual, it is not to exceed the maximum level which can be utilized as a powerful wind plant and the security factor is good for the blade position at the top [36], [37], [40]-[43].

Table 1. Wind speed level above Soil Surfaces

\begin{tabular}{|c|c|l|}
\hline Class & Speed $(\mathrm{m} / \mathrm{s})$ & \multicolumn{1}{c|}{ Condition } \\
\hline 1 & $0.00-0.02$ & - \\
\hline 2 & $0.30-1.50$ & The wind was calm, the smoke straight up \\
\hline 3 & $1.60-3.30$ & Smoke moves in the direction of the wind \\
\hline 4 & $3.40-5.40$ & $\begin{array}{l}\text { The face felt a breeze, leaves swaying slowly, wind direction } \\
\text { moving }\end{array}$ \\
\hline 5 & $5.50-7.90$ & Road dust, paper flying, tree branches sway \\
\hline 6 & $8.00-10.70$ & The twigs of the trees rocked, the flags fluttered \\
\hline 7 & $10.80-13080$ & Big tree branches sway, small choppy water \\
\hline 8 & $13.90-17.10$ & The edges of the trees are curved, the breeze is felt in the ears \\
\hline 9 & $17.20-20.70$ & Can break tree branches, heavy road against the wind \\
\hline 10 & $20.80-24.40$ & Can break tree branches, the house collapsed \\
\hline 11 & $24.50-28.40$ & Can destroy the tree, cause damage \\
\hline 12 & $28.50-32.60$ & Can destroy the tree, cause damage \\
\hline 13 & $32.70-36.90$ & Tornado \\
\hline
\end{tabular}

In particular, determinations of locations that have the potential energy to be an installed port can be considered in accordance with the results of the initial data processing wind energy potential. Location with wind speed not less and more than the class limit of wind speed can be utilized as a powerful wind farm, which is equal to $1.6-17.1 \mathrm{~m} / \mathrm{s}$. This speed will be used to determine the number of blades or windmill blades [44]-[48], [48]-[50]. Turbine blades can utilize the ratio of the turbine blade and turbine spinning at wind speed or tip speed ratio $(\lambda)$ of the designed model as given in following Equation 2. Technically, the required wind speed limits for generators are capable of the producing ideal and effective electrical voltage at wind speeds of $5-8 \mathrm{~m} / \mathrm{s}$ [45], [51]-[58]. These speeds are also capable of rotating generators at speeds of $365-480 \mathrm{rpm}$. By considering these parameters, the blade predictions are provided in Table 2.

$\lambda=\frac{2 . \pi \cdot r \cdot n}{60 . V}$

where $\lambda$ is a tip speed ratio, $\mathrm{r}$ is the wind turbine radius $(\mathrm{m}), \mathrm{v}$ is the wind speed $(\mathrm{m} / \mathrm{s})$, and $\pi$ is 3.14 . 
Table 2. Wind turbine blades

\begin{tabular}{|c|c|}
\hline$\lambda$ & Number of blades \\
\hline 1 & $6-20$ \\
\hline 2 & $4-12$ \\
\hline 3 & $3-6$ \\
\hline 4 & $2-4$ \\
\hline $5-8$ & $2-3$ \\
\hline $8-15$ & $1-2$ \\
\hline
\end{tabular}

Determination of the number of installation points at a particular location associated with coordinated points which can be determined when knowing the width of the sweep of the windmill. Technically, this sweep can be calculated using Equation (3) as follows [16]):

$A=\frac{\pi}{4} D^{2}\left(m^{2}\right)$

where A is the wide sweep of the windmill $\left(\mathrm{m}^{2}\right), \pi$ is $3.14, \mathrm{D}$ is the diameter of the windmill (m).

\section{Procedures of Mitigations}

In these studies, these processes are presented in quantitative and secondary data. In details, the procedures are given in Figure 1 as the block diagram of the study framework. Moreover, the historical data of temperature, air pressure, and wind speed are mitigated for 24 hours in Purwoharjo Sub-district of Banyuwangi Regency. These data are needed in order to know the potential effect on the wind energy source. The data is taken with the map scale of $1 \mathrm{~cm}$ as $1 \mathrm{~km}$ meanwhile the coordinate point covers 205 points of degree North and East Longitude Lines. In details, these points can be seen in Figure 2 and Figure 3 based on the map of Banyuwangi Regency [4].

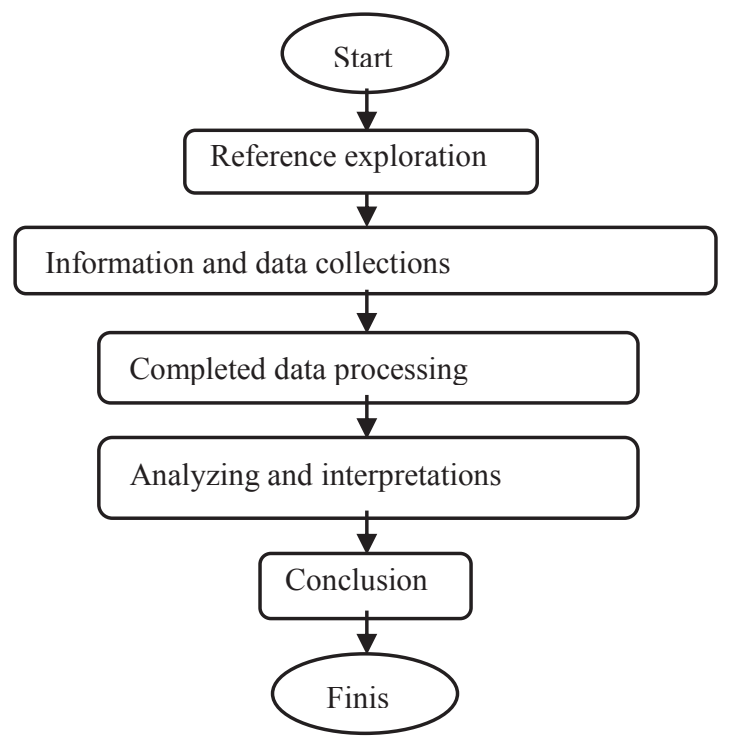

Fig. 1. Block diagram of Research Framework 


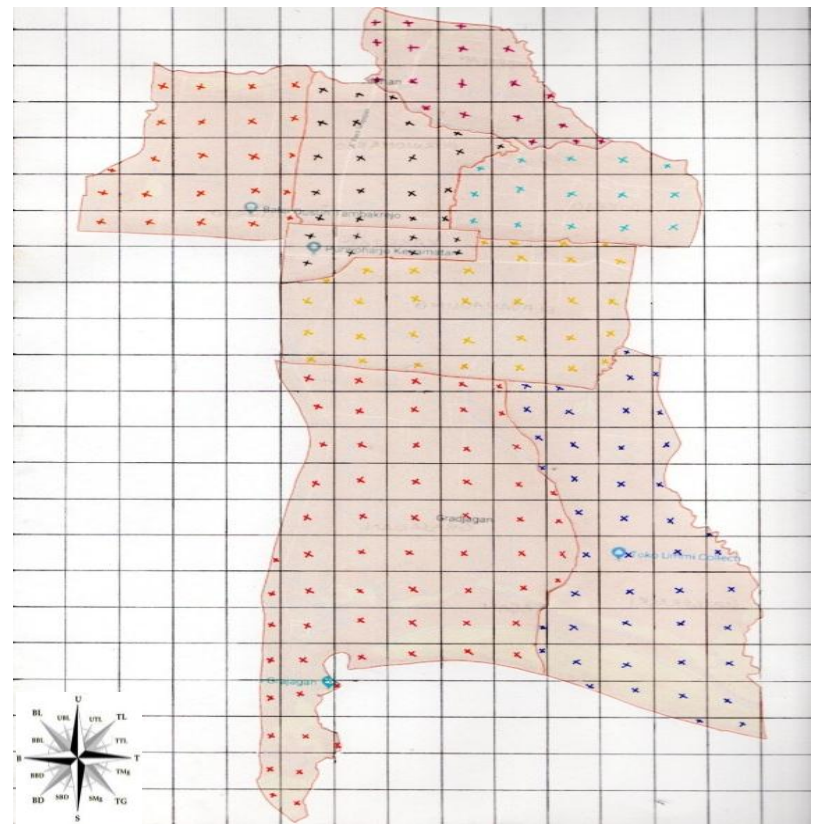

Fig. 2. Mapping coordinations of the potential points.

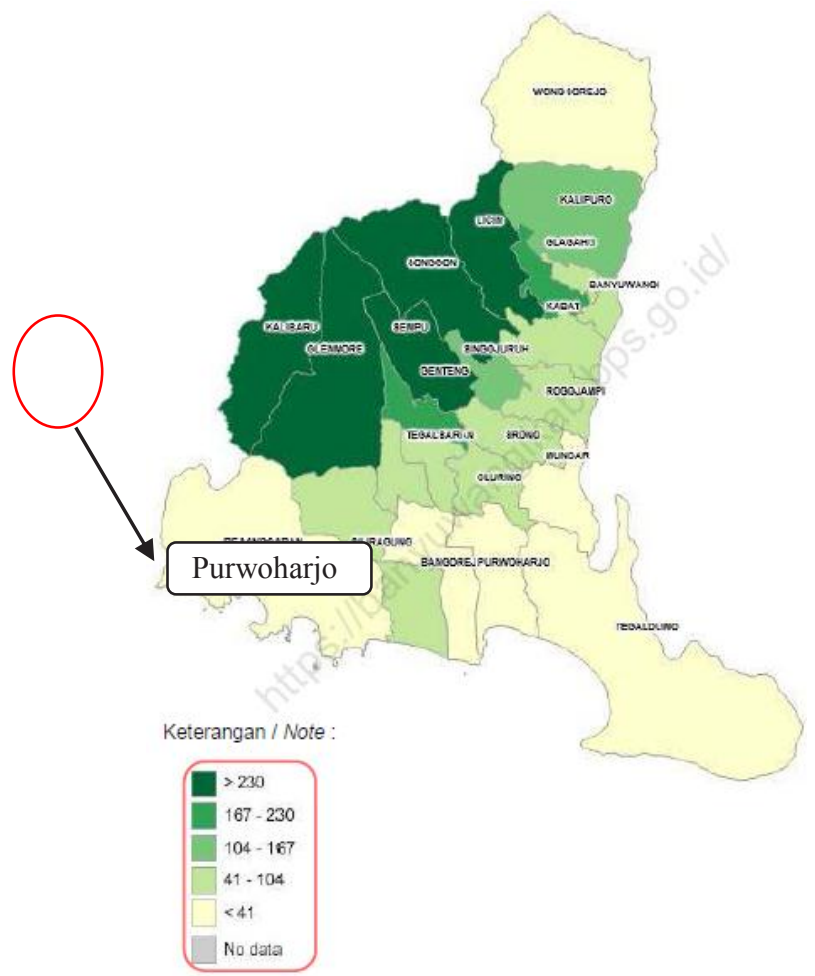

Fig. 3. Map of Banyuwangi Regency 


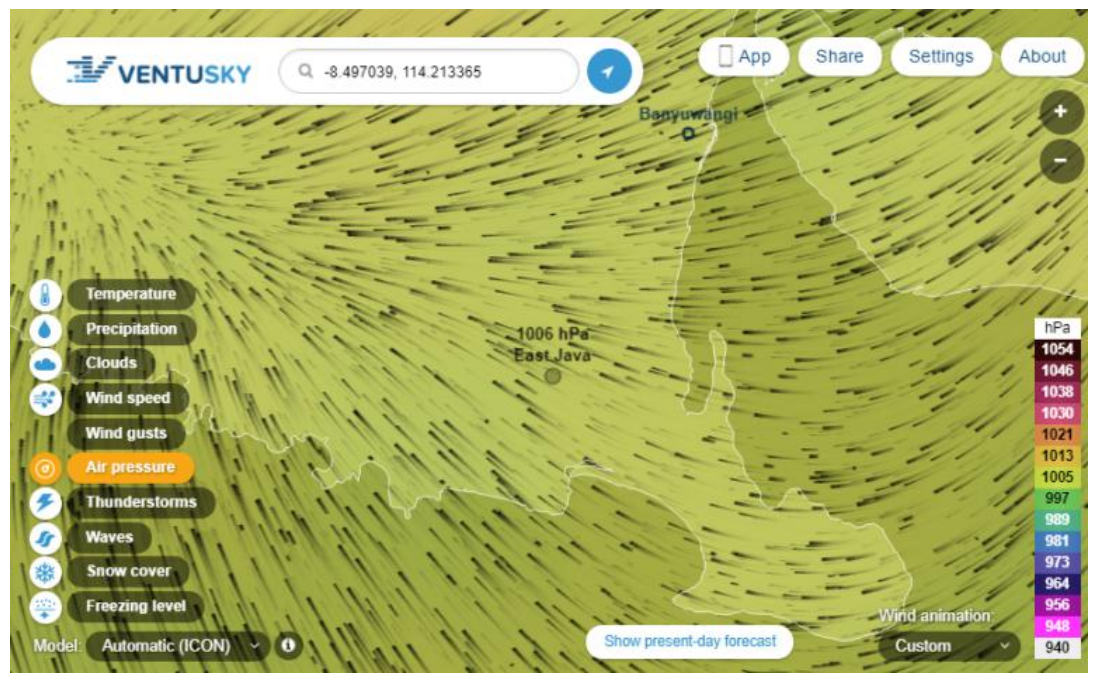

Fig. 4. Ventusky domain web display

In these works, the Ventusky web is useful for collecting operational data of the weather. Moreover, the Ventusky is a web that can be used to check the temperature at different points, rainfall, cloud formation, wind speed, air pressure, thunderstorms, sea waves, snow cover, and freezing point. In details, the Ventusky web view can be seen in Figure 4. The Ventusky has been used by network companies of several online newspapers such as News Corp in the online newspaper "The Sun" to present the latest news on weather conditions or the weather forecasting in the United Kingdom. This web is also used on the Italian newspaper network Lettera43 which is News 3.0 SpA in Milan, where it makes Ventusky a template for real-time weather conditions, time series, and for the next few days on this online news feed website [59]-[61]. By considering these implementations, the data of these studies can be provided at designed coordinates for the potential points associated with the Ventusky performances.

\section{Results and Discussions}

Refer to the processes of determining the locations that have the potential sources to be installed in the field of energy, the number of blades and the number of installation points in a particular location have been obtained the following results as presented in Figure 5, Figure 6, and Figure 7. From Figure 5, it can be seen that the figure shows the potential of energy which is affected by the wind speed. The wind speed deflates between $3.5-4.0 \mathrm{~m} / \mathrm{s}$ with the air mass is provided in a constant of $1.2 \mathrm{~kg} / \mathrm{m}^{3}$. These conditions become the benchmark of the temperature and air pressure while affecting the potential energy sources. Moreover, the magnitude of the wind energy generated at one coordinate point is about $61.02-91.08 \mathrm{Wh}$ with an average of $87.33 \mathrm{Wh}$.

Then, Figure 6 also shows the potential of energy affected by temperature and wind speed, where the affecting air pressure is also not constant. The change of the mass due to the non-constant value of temperature and air pressure, which results in the value of the wind energy are also not equal to the period of the constant type. In details, this result is shown in the wind velocity around $3.5-4.0 \mathrm{~m} / \mathrm{s}$ and a density of $1.17-1.18 \mathrm{~kg} / \mathrm{m}^{3}$, as well as, an average air temperature is $300^{\circ}$ Kelvin while air pressure is defined in an average of 100 - 800 Pascal. Referring to these conditions, the great potential of wind energy 
generated at one point of coordinates is ranged in 59.52 to $89.36 \mathrm{Wh}$ with an average of $85.17 \mathrm{Wh}$.

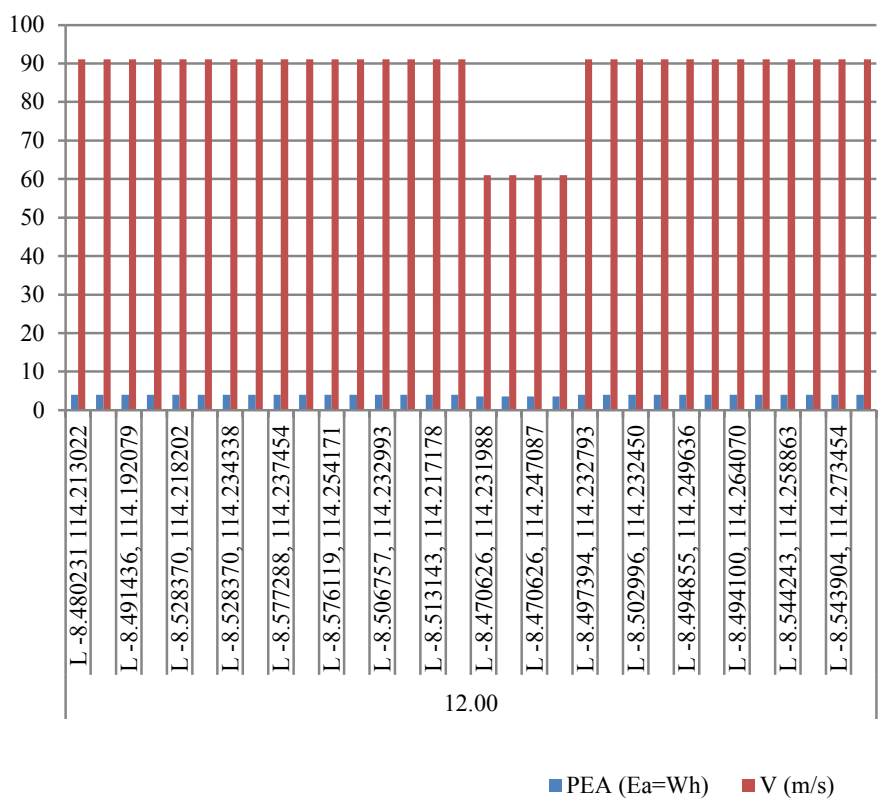

Fig. 5. Wind energy potential affected by wind speed

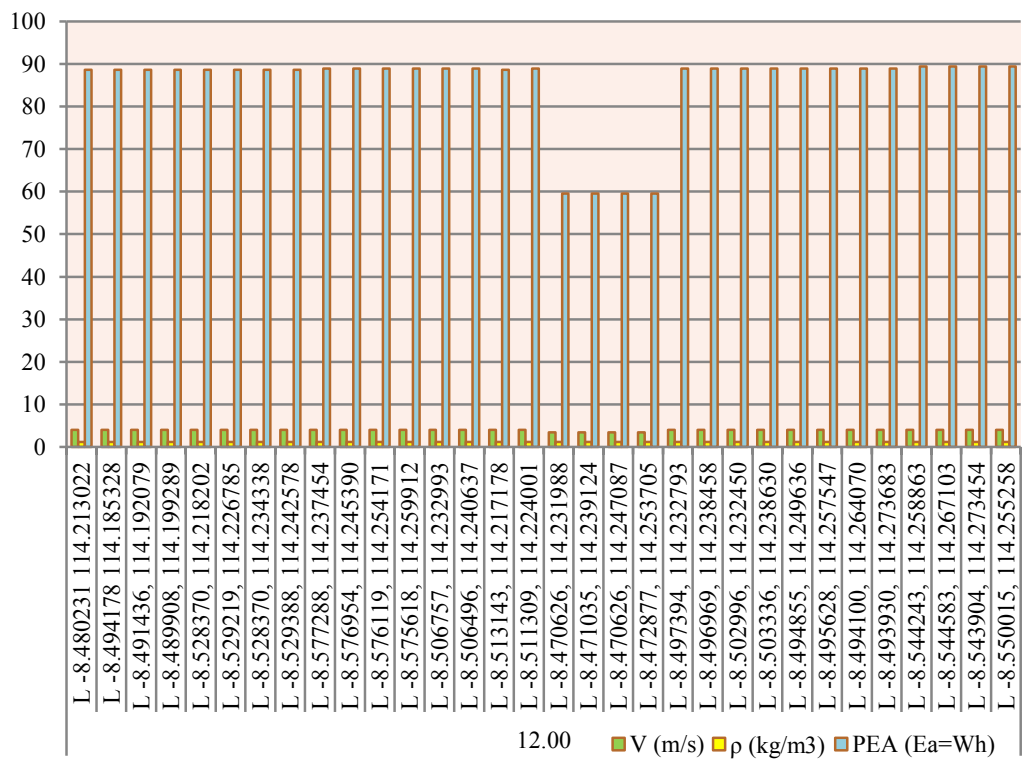

Fig. 6. Wind energy potential affected by temperature and wind speed 


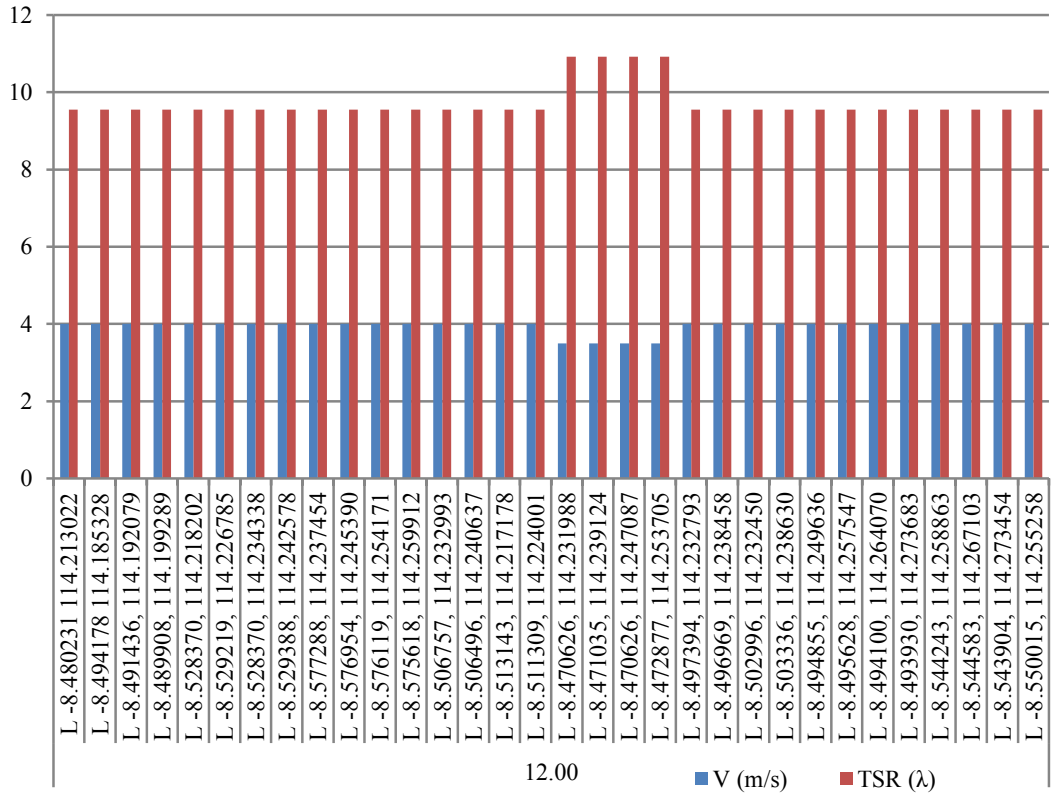

Fig. 7. The tip speed ratio

Based on Figure 7, it can be seen that the tip speed ratio is $9.55-10.92$ and it corresponds to the number of blades covered in Table 2 as detailed in 1 - 2 blades. By considering the width of wind turbine blades of $3.14 \mathrm{~m}^{2}$, then on every $1 \mathrm{~km}^{2}$ of land area can be installed turbine point of 318 dots. By referring to this site, it can also be seen that the optimal wind speed can be utilized at the height of 10 meters above the ground. This optimum speed ranges at 12.00 am with the large wind speed is ranged in $3.5-4.0 \mathrm{~m} / \mathrm{s}$ and the average temperature covers $300^{\circ}$ Kelvin. Therefore, the potential of wind energy generated at one point of the coordinates produces $85.17 \mathrm{Wh}$ for each point.

\section{Conclusion}

Based on the results of the analysis of these works, it can be concluded that the change in wind velocity value is influenced by the temperature at the point where the coordinates are being measured. The temperature change is affected by the changing air pressure at any given time. In addition, changes in temperature and air pressure will affect the value of the type of mass, while changes in wind speed will also affect to the value of generated wind energy. Both parameters will affect to the amount of the potential wind energy. Determining the location of coordinate points can be found based on the topology of the area which will make the wing farm center more effective. Furthermore, reviews regarding blade types and site selection are highly recommended for subsequent next research.

\section{References}

1. S. F. Kennedy. Energy Research \& Social Science (2018)

2. R. Dutu, Energy Policy 98 (2016)

3. A. Schaffartzik, A. Brad, and M. Pichler. Energy Policy 109 (2017)

4. S. Mujiyanto and G. Tiess. Energy Policy 61 (2013) 
5. A. N. Afandi. The 2nd IEEE Conference on Power Engineering and Renewable Energy (ICPERE) (2014)

6. P. J. Burke and S. Kurniawati. Energy Policy 116 (2018)

7. J. J. Chen and M. M. Pitt. Energy Economics 61 (2017)

8. Q. F. Erahman, W. W. Purwanto, M. Sudibandriyo, and A. Hidayatno. Energy 111 (2016)

9. S. M. Lee, Y.-S. Kim, W. Jaung, S. Latifah, M. Afifi, and L. A. Fisher. Energy Policy 85 (2015.)

10. A. N. Afandi. International journal on electrical engineering and informatics $\mathbf{6}$ (2014)

11. Y. Rolik. Procedia Engineering 178 (2017)

12. D. Newell. Land Use Policy 72 (2018)

13. A. B. Asghar and X. Liu. Neurocomputing 287 (2018)

14. A. N. Afandi, Y. Sulistyorini, H. Miyauchi, G. Fujita, X. Z. Gao, and M. El-Shimy, International Journal on Advanced Science, Engineering and Information Technology, 7 (2017)

15. M. EL-Shimy, N. Mostafa, A. N. Afandi, A. M. Sharaf, and M. A. Attia, Mathematics and Computers in Simulation (2018)

16. A. N. Afandi et al. International Review of Electrical Engineering (IREE) 13 (2018)

17. A. Caló, E. Juuso, R. Svento, and E. Pongrácz. IFAC Proceedings 45 (2012)

18. L. Zhou, B. Tinsley, H. Chu, and Z. Xiao. Journal of Atmospheric and SolarTerrestrial Physics 149 (2016)

19. M. Yamamoto and M. Takahashi. Icarus 303 (2018)

20. D. Moravec, V. Barták, V. Puš, and J. Wild. Renewable Energy 123 (20180

21. K. Hansen and B. Vad Mathiesen. Solar Energy 169 (2018)

22. Y. Zhang, Z. Wei, X. Wang, and Y. Zhang. Energy Procedia 142 (2017)

23. Y. Tang, J. Zhong, and M. Bollen. International Journal of Electrical Power \& Energy Systems 95 (2018)

24. F. Chaychizadeh, H. Dehghandorost, A. Aliabadi, and A. Taklifi. Energy Conversion and Management 166 (2018)

25. I. Partridge. Energy Policy 112 (2018)

26. Y. Xie et al., Building and Environment 132 (2018)

27. Muliadi -, E. Ruwaidah, and A. Asyari. ASEAN Journal of Systems Engineering 3 (2015)

28. S. Martosaputro and N. Murti. Energy Procedia 47 (2014)

29. Ismail, S. Kamal, Purnomo, Sarjiya, and B. Hartono. Energy Procedia 65 (2015)

30. Y. Jin, P. Ju, C. Rehtanz, F. Wu, and X. Pan. Applied Energy 222 (2018)

31. M. A. Ebrahim, M. Becherif, and A. Y. Abdelaziz. Sustainable Energy Technologies and Assessments 27 (2018)

32. R. Tiwari and N. R. Babu. Renewable and Sustainable Energy Reviews 66 (2016)

33. Y. Bouzelata, E. Kurt, Y. Uzun, and R. Chenni. Sensors and Actuators A: Physical 273 (2018)

34. Y. Zhang, Y. Xu, H. Guo, X. Zhang, C. Guo, and H. Chen. Renewable Energy 125 (2018)

35. G. Ren, J. Liu, J. Wan, Y. Guo, and D. Yu. Applied Energy 204 (2017)

36. G. Fernandez, H. Usabiaga, and D. Vandepitte. Journal of Wind Engineering and Industrial Aerodynamics 172 (2018)

37. Y. Nihei, Y. Matsuda, S. Kitamura, K. Takaiwa, and N. Kanda. Ocean Engineering 147 (2018)

38. L. Hong and B. Möller. Renewable Energy 44 (2012)

39. A. L. Weisbrich. Refocus 3 (2002) 
40. J. Whale, C. Anderson, R. Bareiss, and S. Wagner. Journal of Wind Engineering and Industrial Aerodynamics 84 (2000)

41. L. Cheng, J. Lin, Y.-Z. Sun, C. Singh, W.-Z. Gao, and X.-M. Qin. IEEE Transactions on Sustainable Energy 3 (2012)

42. D. Jena and S. Rajendran. Renewable and Sustainable Energy Reviews 43 (2015)

43. D. Song, J. Yang, Z. Cai, M. Dong, M. Su, and Y. Wang. Applied Energy 190 (2017)

44. S. Rehman, M. A. Mohandes, and L. M. Alhems. Sustainable Energy Technologies and Assessments 27 (2018)

45. A. B. Asghar and X. Liu. Neurocomputing 272 (2018)

46. A. Sedaghat, A. Hassanzadeh, J. Jamali, A. Mostafaeipour, and W.-H. Chen. Applied Energy 205 (2017)

47. N. S. Pearre and L. G. Swan. Sustainable Energy Technologies and Assessments 27 (2018)

48. C. L. Bottasso, S. Cacciola, and J. Schreiber. Renewable Energy 116 (2018)

49. M. De Lellis, R. Reginatto, R. Saraiva, and A. Trofino. Renewable Energy 127 (2018)

50. F. Golnary and H. Moradi. Renewable Energy (2018)

51. Y. Li, S. Wang, Q. Liu, F. Feng, and K. Tagawa. Cold Regions Science and Technology 145 (2018)

52. J. R. P. Vaz and D. H. Wood. Energy Conversion and Management 126 (2016)

53. A. Rezaeiha, H. Montazeri, and B. Blocken. Energy Conversion and Management 156 (2018)

54. N. Ma et al., Energy 150 (2018)

55. S. Zanforlin and S. Deluca. Energy 148 (2018)

56. Z. Wang and M. Zhuang. Applied Energy 208 (2017)

57. M. Yurdusev, R. Ata, and N. Cetin. Energy 31 (2006)

58. M. Yin, Z. Yang, Y. Xu, J. Liu, L. Zhou, and Y. Zou. Applied Energy 221 (2018)

59. "Online World Weather Forecast Application: Ventusky." [Online]. Available: https://www.techwareguide.com/free-online-world-weather-forecast-applicationventusky/. [Accessed: 06-May-2018].

60. "Ventusky is a beautiful weather map quite unlike any other | Digital Trends." [Online]. Available: https://www.digitaltrends.com/cool-tech/ventusky-weather-map/. [Accessed: 06-May-2018].

61. "Ventusky - Wind, Rain and Temperature Maps." [Online]. Available: https://www.ventusky.com/. [Accessed: 06-May-2018]. 